MAN TRUCK \& BUS AG

\section{Antriebsanordnung für}

Nutzfahrzeuge

In der Erfindung wird eine Antriebsanordnung für Kraftfahrzeuge, insbesondere Nutzfahrzeuge dargestellt. Bei niedrigen Übersetzungen treten in der Antriebskonfiguration von Nutzfahrzeugen oft hohe Antriebsmomente auf, deren Reaktionsmomente über die Motorlagerung abgestützt werden müssen beziehungsweise Verspannungen und Überlastungen im Antriebsstrang zur Folge haben.

Aufgabe der Erfindung ist es, eine Antriebsanordnung vorzuschlagen, die neben baulichen und konstruktiven Vorteilen eine weitgehende Eliminierung derartiger Reaktionsmomente erlaubt oder deren Höhe und Wirkrichtung gezielt einstellbar macht. Die Antriebsanordnung besteht aus einer Maschine, einem nachgeschalteten Getriebe und einem Differenzial, die zu einer Antriebseinheit fest zusammengebaut worden sind. Die Aufgabe wird dadurch gelöst, dass das Differenzial mit seinen Ausgangselementen auf zwei im Antrieb drehbar gelagerte und gegenläufig angetriebene Abtriebswellen wirkt. Diese sind mit je einer die angetriebenen Räder des Kraftfahrzeugs antreibenden Gelenkwelle verbunden. fs

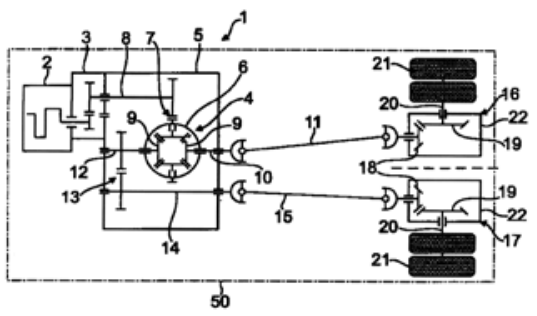

Offenlegungsschrift: DE 102010012085 A1 Anmeldetag: 19.03.2010

Veröffentlichungstag: 15.12.2011
Höhenverstellung für eine

Radaufhängung

Insbesondere tiefliegende Sportwagen haben bei der Einfahrt in eine Tiefgarage das Problem, dass der vordere Fahrzeugbereich den Boden berührt. Bisherige Lösungen des Problems hatten aufgrund der konstruktiven Gegebenheiten den Nachteil, dass eine Höhenverstellung vergleichsweise lange dauert.

Das Patent hat die Aufgabe, diesen Nachteil zu reduzieren. Ermöglicht wird das durch eine an einem Dämpferrohr befestigte Innenhülse mit Führungsbahn, in der wenigstens ein Kulissenelement geführt aufgenommen ist. Eine Außenhülse, die koaxial zu der Innenhülse angeordnet ist, steht mit dem Kulissenelement wenigstens in Umfangsrichtung im Eingriff. Weiterhin ist eine Zwischenhülse für ein Anliegen gegen einen Federteller vorhanden, die zwischen der Innen- und Außenhülse und koaxial zu diesen angeordnet ist. Die Zwischenhülse steht mit dem Kulissenelement wenigstens in axialer Richtung im Eingriff. Eine Antriebseinrichtung zum Drehen der Außenhülse in Umfangsrichtung ermöglicht ein axiales Bewegen der Zwischenhülse und dadurch ein Bewegen eines Federtellers der Radaufhängung. fs

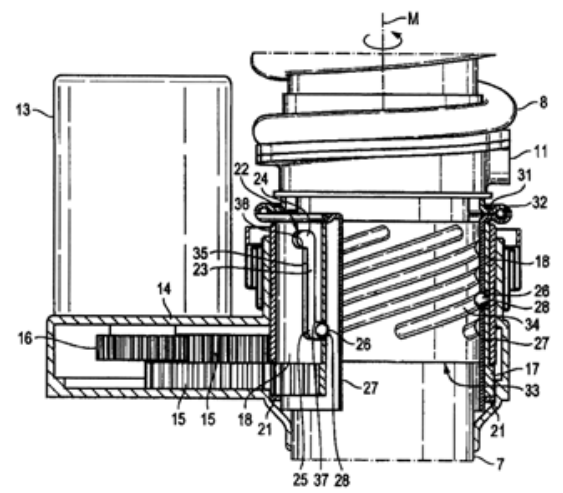

Offenlegungsschrift: DE 102010017352 A1 Anmeldetag: 14.06.2010

Veröffentlichungstag: 15.12.2011
AUDI AG

Kraftfahrzeugtür mit einem

Seitenaufprallschutz

Um den Seitenaufprallschutz bei Pkw zu verbessern, ist in den Kraftfahrzeugtüren ein Seitenaufprallträger integriert, der mit entsprechenden Befestigungselementen fest mit der Umgebung verbunden wird. Die Erfindung hat die Aufgabe, ein AusreiBen der Verbindungselemente (Schrauben, Nieten etc.) zwischen Seitenaufprallträger und Innenblech der Kraftfahrzeugtür erheblich zu reduzieren.

Ermöglicht wird das durch eine Konstruktion, wobei der mit dem Innenblech der Tür fest verbundene Seitenaufprallträger einen flächig ausgebildeten Endbereich aufweist, auf dem das Innenblech der Tür aufliegt. Der flächige Endbereich des Seitenaufprallträgers und das Innenblech haben jeweils fluchtend zueinander angeordnete Durchgangsöffnungen. Innenblech und Aufprallträger sind mittels einer die Durchgangsöffnungen durchfassenden Schraube kraftschlüssig verbunden. Die Durchgangsöffnung des Innenblechs hat einen kragenförmig ausgebildeten Randbereich, der in axialer Richtung mindestens bereichsweise in die entsprechende Durchgangsöffnung des Endbereichs des Seitenaufprallträgers hineinreicht. $f_{s}$

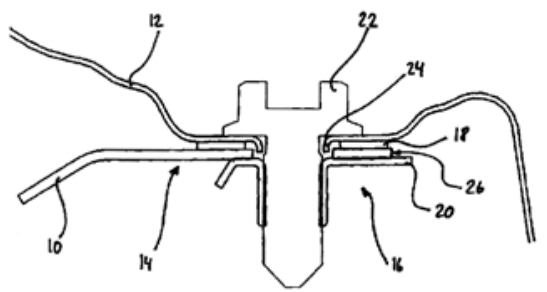

Offenlegungsschrift: DE 102006046815 B4 Anmeldetag: 02.10.2006

Veröffentlichungstag: 15.12.2011 